\title{
The limits of ontological critique: from judgmental rationality to justification
}

Article

Accepted Version

Al Amoudi, I. and Latsis, J. (2017) The limits of ontological critique: from judgmental rationality to justification. Cambridge Journal of Economics, 41 (5). pp. 1303-1321. ISSN 1464-3545 doi: https://doi.org/10.1093/cje/bex039 Available at https://centaur.reading.ac.uk/70797/

It is advisable to refer to the publisher's version if you intend to cite from the work. See Guidance on citing.

To link to this article DOI: http://dx.doi.org/10.1093/cje/bex039

Publisher: Oxford University Press

All outputs in CentAUR are protected by Intellectual Property Rights law, including copyright law. Copyright and IPR is retained by the creators or other copyright holders. Terms and conditions for use of this material are defined in the End User Agreement.

\section{www.reading.ac.uk/centaur}

\section{CentAUR}

Central Archive at the University of Reading

Reading's research outputs online 


\section{The Limits of Ontological Critique: from Judgmental Rationality to Justification}

Word count: 9,596 words

Keywords: Critical realism, économie des conventions, mathematical modelling, judgemental rationality, justification.

\section{$\underline{\text { Abstract }}$}

The Cambridge Social Ontology (CSO) programme's inability to generate a meaningful dialogue with mainstream economics is difficult to understand by mere reference to judgmental rationality and without reference to CSO's ideological configuration. Our paper uses an économie des conventions framework to draw systematic comparisons between CSO's ideological configuration and the ideological configurations of mainstream economic theories and practice. The resulting analysis helps us to understand not only why CSO generated little response from the mainstream, but also how CSO might renew its critique in ways that might be more likely to produce a response.

\section{$\underline{\text { Introduction }}$}

Since the late 1980s, defenders of what has come to be called Cambridge Social Ontology (CSO) have seen it as a foil for mainstream economic modelling. Tony Lawson (1997) constructed and elaborated a methodological critique which attempts to undercut the more traditional theoretical objections offered by most heterodox economists. Yet after nearly thirty years of prolific intellectual activity, CSO has received few direct responses from mainstream modellers. Instead, both critical and supportive voices have come almost entirely from outside the mainstream and from across the other social sciences.

Some methodologists (Colander et al 2004; Davis 2006) have tried to explain the lack of response by reference to changing trends within economics. They argue that heterodox critics of mainstream economics in general, and Lawson in particular, provide outdated critiques and do not engage adequately with current trends in economics. More specifically, these commentators claim that what could previously have been described as a cohesive mainstream with a relatively limited set of assumptions and methods has been supplanted by a more heterogeneous group of cutting edge research programmes that recognise both the dynamics and complexity of economic systems and as such are sometimes (perhaps even often) indistinguishable from what Lawson and CSO refer to as the heterodoxy. This argument appears to at least partially lay responsibility for the inability to engage with mainstream economics at the door of proponents of CSO: they have failed to recognise the diversity and dynamism of current 'mainstream' approaches, which amongst other things renders their critique irrelevant since the new approaches have taken on 'heterodox' assumptions. It is not within the remit of this article to specifically refute these arguments, which, in our opinion, were answered directly by Lawson himself in his response to Davis and elsewhere (Lawson 2009: 103-106, Lawson 2006: 491-495). 
However, it is worth noting that the research programmes that Davis and Colander cite as examples of cutting edge mainstream research all employ mathematical deductivist methods and present their analytical findings in the form of models (for a specific example, see Latsis \& Repapis 2014). Our position, contra Davis and Colander, is that the limited impact of CSO arguments on the mainstream does not come from CSO's failure to engage with mainstream ideas, but with the mainstream's lack of interest in considering criticism levelled by proponents of CSO and respond in a coherent manner (though there are inevitably a small number of exceptions). Given the scope and ambition of the CSO critique, this relative silence is, prima facie, rather surprising. While claims that CSO has missed mainstream economics' renewed assumptions are unconvincing, we are left with a puzzle: why is CSO's critique perceived as irrelevant and devoid of value from mainstream economics' perspective when it seems relevant and valuable from its own perspective?

One way of explaining the failure of critical dialogue and debate is to invoke the existence of competing paradigms locked in their own language games and unable to address each other directly. But, in this case, a simplistic Kuhnian interpretation is not convincing for at least two reasons. First CSO is a philosophical and methodological critique, not a competing theoretical research paradigm. Second, CSO explicitly endorses 'judgmental rationality', which is the view that there are universal/isable ways of discriminating between theories, and it therefore rejects the Kuhnian notion of incommensurability.

Some commentators (e.g. Lawson 2007) have already pointed out that the absence of critical engagement and dialogue may indicate psychological or social-psychological characteristics that are typically favoured within the mainstream profession, but have the perverse side-effect of both narrowing the field and limiting discussions with outsiders. And recent sociological contributions (e.g. Fourcade et al. 2015) explain how the lack of engagement is facilitated by the current institutional environment. But these undoubtedly valuable psychological and sociological insights do not provide a theoretical explanation of why CSO's critique has fallen on deaf ears. It is our contention that the économie des conventions (EC), with its explicit focus on situated judgement, the construction of legitimacy, critique and agreement can provide a compelling framework within which to understand CSO's limited impact on the mainstream.

Our argument in the remainder of this article has the following structure. First we take stock of CSO's inability to engage in dialogue with, let alone affect the dominance of, mainstream modelling. Second, we explain the notion of judgmental rationality in the critical realist philosophical tradition and link it to the project of social ontology more generally and the Cambridge variant in particular. Third, we outline the core insights of the EC on the role of justification in the social sciences, focussing on the contribution of Thevenot and Boltanski in their book On Justification (2006) and on their important follow-up paper 'The reality of moral expectations: a sociology of situated judgement' (Boltanski \& Thevenot 2000). Fourth, we use the EC framework to compare and contrast the different forms of judgement that are deemed to be legitimate within CSO and mainstream economics. The final part of our article discusses the broader implications of our findings for social ontology and for future discussions between CSO and $\mathrm{EC}$ and between CSO and mainstream economics 


\section{The Dialogue of the Deaf}

Starting in the late 1980s, Tony Lawson's contributions have emphasised the lack of fit between the methods of modern mainstream economics and the nature of social reality. The basis of his critique of the mainstream has been that the mathematical modelling methods employed by mainstream economists presuppose that the social world is a closed system made up of atomistic individuals. His contention is that, in contrast to the presuppositions of the mainstream, the social world is open and made up of complex, reflexive subjects and emergent structures. He draws on Roy Bhaskar's philosophical writings (Bhaskar 1975/2008; 1979/2014), the history of economic thought (Kline 1964; Henry 1997; Gingras 2001) and on contemporary contributions to heterodox economics to show that an adequate economic theory can be constructed using different methods and relying on a different philosophical ontology ${ }^{1}-$ one that is consistent with his own conception of the nature of social reality. Lawson employs two types of arguments to bolster his case. The first is an immanent critique ${ }^{2}$ showing how mainstream economics fails by its own empirical standards of testing and prediction (see e.g. Lawson, 1997: 3-11). The repeated failure of economics is then used as a point of departure for an ontological discussion of the nature of social reality and economic systems of production and exchange (see esp. Lawson 2003). The second discusses the nature of social reality, and the possibility of its systematic study, by appealing directly to our experience of social life and the common sense knowledge that all appropriately socialised human beings need to carry out their lives (see e.g. Lawson, 1997 157-187). Together, these arguments provide a powerful case against the scientific status of mainstream modelling and the conception of social reality that it implicitly presupposes.

After the publication of Economics and Reality, there was a significant critical response to the CSO project and to Tony Lawson's writings in particular. Participants in the debate came from the philosophy of economics (e.g. Hausman 1998, Hausman 1999, Cottrell 1998, Parsons 1999) and from heterodox economics (e.g. Hodgson 1999, Dow 1999). Much of this early debate was reviewed and discussed in an edited volume by Steve Fleetwood (Fleetwood 1999). No mainstream economist engaged in this stage of the debate despite the fact that many of Lawson's ideas that crystallised in the book had initially been published in a series of journal articles in the late 1980s and early 1990s.

In subsequent years Lawson and other members of CSO continued to publish critical material about mathematical modelling in economics and extended their critique to specific sectors of the economy (eg Fleetwood 2006, Morgan 2009) and specific economic techniques (e.g. Lawson 1989, Pratten 2005). There was also a concerted effort to construct an alternative philosophical ontology in which heterodox economists could anchor their different approaches (Lawson 2003, 2006). Again, these efforts received considerable attention in heterodox and methodology circles, as well as growing interest from sociology (e.g. Elder-Vass 2010) management studies (e.g. AlAmoudi \& Willmott 2011; Brown and Roberts 2014; Fleetwood 2005; Reed 1997) and several other social science disciplines. Yet, once again, there was virtually no response from mainstream economists with the notable exception of one short chapter by the

\footnotetext{
${ }^{1}$ We define 'philosophical ontology' more precisely below.

${ }^{2}$ By immanent critique we mean a critique that takes the objectives of the target theory as given and proceeds by 'exposing internal inconsistencies in beliefs implicit in practices, or demonstrating how beliefs held cannot accommodate practices actually achieved.' (Lawson 1997: 211).
} 
Nobel prize winning econometrician Clive Granger (2004) in an edited collection (Lewis 2004).

The latter is an interesting piece because it combines sociological and substantive arguments in its defence of the mainstream. In the first part of the paper Granger points out that a critique based on the failure of modern mainstream economics faces the empirical counter argument that the discipline is (or was at the time), by all sociological measures, in rude health: journals, conferences, departments and prizes abound; the discipline recruits many students at post graduate level; and economists are often paid to advise governments and private firms. Granger also provides a more substantive riposte to some parts of Lawson's argument. Yet this riposte is notable for both its modesty and its narrowness. Granger doesn't claim to speak for economists, but merely for econometricians; he doesn't defend high theory, but merely the use of specific statistical techniques and tools within econometrics. Indeed he is sometimes critical of econometricians, but alludes (in the same way as Davis and Colander) to recent developments that purportedly resolve some of the empirical worries voiced by Lawson and other proponents of CSO. On meta-theory he says little of note, except to point out that econometricians assume the existence of a 'data generating mechanism' (which he equates with CSO's conception of social reality), and that it is 'convenient to start' with the assumption that economics is a decision science (which he then couches in terms of methodological individualism and rational choice). Thus, his philosophical assumptions are asserted without argument nor appeal to previous arguments, apparently without an appreciation of their fundamental importance for any subsequent theorisation. His intervention provides an interesting insight into the level at which the top of the profession is willing to engage: in short opinion pieces published in edited collections that make no attempt to systematically rebut the key arguments of the opposition camp and that partially rely on the profession's prestige to answer a substantive critique of the theory.

It is notable that some contributors to the methodological debate have suggested reasons for the lack of engagement of the mainstream. The papers in Fullbrook (2009), in particular, provide a number of competing explanations that are worthy of consideration. Parenthetically, it should be noted that these contributions do not set out with the objective of explaining the limited impact of CSO on the modelling project (as we do). Instead, they do so implicitly, as part of the critiques the authors provide of Lawson's published work.

The explanations fall into three broad categories. The first focuses on the metatheoretical nature of the CSO project. Davidsen (2009) argues that ontological critique cannot succeed so long as it remains at the level of what Lawson calls 'philosophical ontology', namely the abstract conception of the social world upon which all economic theorising must rest in order for modelling methods to work. Instead, he calls for domain specific contributions that intervene directly in the theoretical debates of the mainstream. The idea is that economists would be compelled to respond if only CSO proposed new approaches and solutions to the problems identified by economists ${ }^{3}$.

\footnotetext{
${ }^{3}$ It is worth noting that that Tony Lawson has contributed significantly at the level of social scientific ontology in recent years, developing particular accounts of the nature of the corporation (Lawson 2014; 2015) and of money (2012a, 2016). Unfortunately, it seems unlikely that this will generate much by way of interaction with the mainstream even if it may lead to an enriched discussion with other heterodox economists with interests in these areas.
} 
The second explanation focuses on the discourse of economics and, in particular, the use of mathematical language to express and investigate economic ideas. Both Downward and Mearman (2009) and Hodgson (2009) question Lawson's critique of the mathematical method in economics, the former with respect to econometrics and the latter with respect to modelling more generally. The disagreements share a family resemblance in that all three authors argue that, despite the strength of certain elements of the CSO critique, its impact is limited by the fact that Lawson appears to wholly reject the lingua franca of modern economics: deductive modelling. Adoption of some part of the modelling apparatus is therefore seen as a desirable requirement for a dialogue between CSO and mainstream economics.

The third explanation, put forward by Bernard Guerrien (2009), focuses on ideology. Guerrien concludes that the insistence on mainstream modelling cannot be justified scientifically and masks a commitment to a neoclassical ideology that supports the spread and development of free market systems. The reason that mainstream economists have failed to engage with CSO is then readily explained by the presence of a fundamental ideological conflict between the two parties since Lawson and other proponents of CSO do not share their dogmatic commitment to free markets.

The first two arguments may well be relevant sociological explanations of why CSO has been ignored by the mainstream. Indeed, recent work by sociologists on the structure and functioning of the economics profession (Fourcade et al 2015) has found that economists are hierarchical, inward looking, extremely committed to the technical toolkit of the profession, and increasingly focussed on fields of empirical application of their models at the expense of meta-theory. However, the third explanation may (at least partially) hit its mark. In his response to Guerrien (Lawson 2009) and a subsequent paper (Lawson 2012b), Lawson acknowledges the importance of ideology, understood as: 'a relatively unchallenged set of (...) background ideas that every society or community possesses which forms the basis, or significantly informs, general opinion or "common sense", a basis that remains somewhat invisible to most of its members, appearing as "neutral", resting on preconceptions that are largely unexamined' (Lawson 2012b: 5). Contrary to Guerrien, however, Lawson identifies unquestioned reliance on mathematical modelling - rather than unquestioned optimism about free markets - as the central ideological element responsible for mainstream economics' rigidity and failure. $^{4}$

Yet, while Lawson's analysis of mainstream economics' ideology is (in our view) convincing, it nonetheless begs the question of its own ideological assumptions and of CSO's capacity to critically reflect, identify and surmount them. CSO's adoption of the critical realist conception of judgemental rationality seems, prima facie, to provide a safeguard against unwarranted doctrinal assumptions, that is, against ideology of the sort outlined above. But does it? This is the question to which turn in the next section.

\section{Social Ontology and the Judgment Gap}

\footnotetext{
${ }^{4}$ This debate about the relative role of market ideology vs mathematical formalism as the touchstone of mainstream economics has continued with the recent publication of two reactions to Lawson's 2012b paper by Milonakis (mimeo?/ this volume?) and O’Boyle and McDonough (2017).
} 
Since the publication of Roy Bhaskar's pioneering early works in the philosophy of science (Bhaskar 1975; 1979), proponents of Critical Realism have argued that their contributions are founded upon three fundamental tenets often referred to as ontological realism, epistemological relativism and judgmental rationality. Simplifying somewhat, these terms signal the acceptance of:

1. A partly mind independent world of structured entities, including causal mechanisms, that underpin our experiences (ontological realism).

2. A set of theories intended to describe those entities. All theories are socially produced; they are fallible and their meaningfulness is context specific (epistemological relativism).

3. An ability by scientists, or some other relevant epistemic community, to agree which theories provide the most convincing connections between observed events and those mechanisms that cause them to happen (judgmental rationality).

Despite continuing discussion of these foundational tenets (e.g. Groff 2000; Bhaskar 1979/2014), subsequent contributions to social ontology (including CSO) have tended to take all three more or less for granted. And, when combined, they present an enticing perspective for critical-minded scholars. The commitment to ontological realism safeguards against the assumption -- which is often tacitly made by idealist and postmodernist approaches -- that social reality is entirely created by our conceptions of it. The commitment to epistemological relativism provides a defence against the charge of absolutism and scientism that dogs positivist contributions (especially in the social sciences). But it is the appeal to judgmental rationality that holds it all together. Scientific theories must, somehow, connect to underlying causal mechanisms and scientists must, somehow, be able to identify such connections and rate theories accordingly. If judgmental rationality cannot help with the task of adjudicating between theories, then the critical resources of social ontologists are stripped away and there is a risk that the position becomes a species of irrationalism. But abandoning judgmental rationality in the social sciences is also problematic for ethical reasons. Indeed, epistemological judgments relative to theories (eg. which one is more plausible?) are inseparable from ethical judgments relative to social forms (which one is more conducive to human flourishing?). Put simply, if we can agree that a certain social form impedes human flourishing, then we can also agree, ceteris paribus, that this social form should be eliminated, transformed or replaced ${ }^{5}$.

Bhaskar insists that scientific practice is a social process which depends on intersubjective agreement within a community of scientists, and that their collective judgment remains fallible and potentially subject to revision (see esp. Bhaskar 2008: 185-228). He also rejects a correspondence theory of truth and states that knowledge of the underlying causal mechanisms is always knowledge under some particular theoretical description (Bhaskar 2008: 241). However, he maintains that at least some

\footnotetext{
${ }^{5}$ Although Bhaskar claims that he dedicated his third book Scientific Realism and Human Emancipation to the third tenet of critical realism (judgmental rationality), this is not exactly what we have found on the several occasions when we have read it. The book offers first and foremost an extremely sophisticated, and exploratory, critique of positivism under its various guises. While the chapter on 'critical naturalism and the dialectic of human emancipation' features important arguments on the link between facts and values, there is very little on the social processes through which agents engage in judgementally rational discussion
} 
of the results of scientific enquiry can be 'detached' from theory and treated as truths upon which further theories can be built. In order for this to be possible, however, theoretical controversies must be settled on rational grounds. How these controversies are settled is a matter for scientists to decide, but the mere presence of intersubjective agreement is clearly not sufficient. In A Realist Theory of Science, Bhaskar emphasises the role of explanatory power as a key criterion, but does not give a comprehensive account of the underpinnings of rational scientific judgment:

"In order to render intelligible scientific change and to reconcile it with the idea of scientific progress we must have the concept of an ontological realm, of objects apart from our descriptions of them. We can then allow, for example, that theory Ta is preferable to theory $\mathrm{Tb}$, even if in the terminology of Kuhn and Feyerabend it is 'incommensurable' with it, if theory Ta can explain under its descriptions almost all the phenomena 1 ...pn that Tb can explain under its descriptions Bp1... Bpn plus some significant phenomena that Tb cannot explain." (Bhaskar 2008: 240)

Writing from within the critical realist tradition, Ruth Groff (2000) has noted that judgmental rationality remains largely unarticulated in Bhaskar's early philosophical writings and was substituted with the problematic concept of 'alethic truth' in his later writings ${ }^{6}$. She notes that:

"From the beginning, there was the question of the relationship between ontological realism and rationality at the level of judgment. Despite Bhaskar's early claim that "there is no way in which we can look at the world and then at a sentence and ask whether they fit" (Bhaskar 1979: 249), there has been a presumption, I would argue, at least among readers of Bhaskar, that accepted scientific theories do achieve such a fitand that accountability to the idea of such a fit is precisely what is meant by the notion of rationality at the level of judgment. Moreover, there has been a tendency to regard the principle of ontological realism as providing an anchor for, and as thereby authorizing, judgmental rationality so construed. According to this line of reasoning, it is possible to discriminate between competing theories on rational grounds exactly because there is a real, intransitive domain, the causal structure of which may be more or less accurately identified by competing causal accounts." (Groff 2000: 418)

More specifically, Groff's contribution points to a 'judgment gap' that, we believe, persists today in the literature on social ontology: if one takes the notion of epistemological relativism seriously, then the challenge is to elaborate a more comprehensive account of how certain intersubjective agreements come to be justified as scientifically legitimate whilst others do not.

How does this apply to CSO more specifically? As we saw above, Lawson's critique is grounded in ontology - more specifically the mismatch between philosophical ontology and mainstream economic theory - but he also recognises that theories are human constructions that are separate from the underlying mechanisms and processes that they aim to describe. Early on, he subscribed explicitly to Bhaskar's three tenets, using the critical realist concepts of the transitive and intransitive domains:

\footnotetext{
${ }^{6}$ The first point at least is acknowledged by Bhaskar in a more recent contribution (Bhaskar 2007).
} 
"If knowledge is not merely given in experience, it is hardly intelligible that it is created out of nothing. It must, then, come about through a transformation of pre-existing knowledge-like materials. In other words, it is necessary ... to recognise a transitive dimension to knowledge, or epistemology to complement the intransitive dimension to knowledge, or ontology, already established. That is, it is necessary to recognise a dimension of transitive objects of knowledge, including facts, observations, theories, hypotheses, guesses, hunches, intuitions, speculations, anomalies, etc., which condition all further knowledge, and in particular facilitate, and come to be actively transformed through, the laborious social practice of science. In short, knowledge must be recognised as a produced means of production (of further knowledge) and science as an ongoing transformative social activity." (Lawson 1997: 25)

But Lawson's focus (unlike Bhaskar's) is economics and the contested nature of the field means that defining progress and justifying theory choice are never far from the forefront of his mind. Thus he provides a more elaborate account of explanatory power than the sketch provided by Bhaskar: the theory of contrastive explanation. This position has been developed at length subsequently, so we will only provide a brief description here. The essence of the argument is that knowledge of the social world is derived from the identification of rough empirical patterns termed 'demi-regs'. Demiregs are imperfect associations between two or more measured variables that may hint at the operation of an underlying causal mechanism. When our expectations of such patterns within a specified 'contrast space' are flouted, for instance because two patterns that we expect to be similar (crop yields in neighbouring fields) turn out to be different, then this can provide insight into the operation of the underlying mechanism. In the social sciences in particular, insights can be of two basic sorts:

"The basis of our surprise may indeed be a new causal factor coming into play, but equally it may merely be that our prior assessment of the nature of the contrast space was significantly in error all along. From such considerations we can see that the possibility of a progressive transformation in our knowledge does not require that we have judged the contrast space correctly, merely that we had rational grounds for the judgment formed' (Lawson 2003: 91, my italics)

Despite his valuable elaboration of the concept of explanatory power applied to the social sciences, Lawson's position effectively inherits the questions raised about Bhaskar's judgment gap. The progress of social science is fundamentally dependent on judgmental rationality, which is responsible for setting the limits of the contrast space, for forming expectations based on anterior knowledge, for qualifying observed situations as 'surprises' or contradictions to expectations, and for prompting a need for revision of existing theory and further theoretical elaboration. We can see, even in the simple case of identifying mechanisms behind unequal crop growth in a given field, that there is no ready-made or rationally deducible formula for setting a contrast space and deriving conclusions from it. The presence of a river, or parasitic animals or shaded areas all seem prima facie equally plausible candidates that are neither exclusive nor exhaustive. Yet, to avoid irrationalism, Lawson requires the setting of the contrast space, and the conclusions drawn from it, to be established on some grounds other than context specific intersubjective agreement. It is not legitimate for two scientists to decide to attribute unequal crop growth to parasites on the sole basis that doing so would please a friend owning a pest-control company. In other words, a properly scientific approach does not only attempt to establish agreement among present participants, but 
it should also seek to secure agreement from putative participants as well. Indeed, Lawson's critique of mainstream economics would suffer significantly if this were not the case as it would be objected that he is attempting to replace the mainstream economics project with an incoherent programme that can only envisage local agreements and that is not conducive to growing or refining knowledge over time.

This leaves CSO in a similar position to the CR-inspired philosophical research that preceded it. Since judgmental rationality cannot simply be read off from ontological realism, proponents cannot ignore the problem of how justification is constructed in the social sciences. The CSO critique of mainstream economics exacerbates this need because there is widespread intersubjective agreement amongst mainstream economists that their methods are appropriate and their core theoretical and empirical findings are reliable. A judgmental relativist would be forced to either accept this position, or cast his or her critique purely in terms of competing ideologies, something that Lawson has repeatedly resisted doing (see our argument in Part 1). Needless to say, we do not consider this to be a fatal flaw in the CSO project, but it does indicate an important area for theoretical development. We do not believe that proponents of CSO are engaged in an internal debate which relies on purely local / intersubjective justificatory mechanisms (indeed their explicit rejection of postmodernism is strong evidence of this position). Out of instinct and common sense, most of their studies seek to secure some form of potentially universalisable justifiability: they are intended to convince their interlocutors through some combination of logical argument, demonstrations of explanatory power, and empirical evidence. And yet this universalisable justifiability fails to convince mainstream economists. It remains unclear therefore what the conditions of possibility of this universalisable justifiability are. What are its limits? On what grounds is it criticisable by mainstream economics? And how might such a critique ultimately be deemed legitimate?

One difficulty facing CSO, like any other research programme, is that, by definition, its ideological assumptions are opaque to it. Fortunately, ideological opacity does not imply impenetrability and can be surmounted to some extent. Our current project is relatively modest as we endeavour to clarify some, rather than all, the assumptions of CSO. Yet, even such a pared-down endeavour is not trivial. How can a given project clarify at least some of its own unseen assumptions?

Our chosen approach consists in pursuing our analysis from a different, yet largely congruent, interpretative framework. This shift allows us to objectify CSO and step back from its (non-) debate with mainstream economics. Our intention in the rest of the paper is therefore to treat CSO as an object of analysis rather than as an analytical resource. Metaphorically, we are trying to see our own eyes but need a mirror to do so. The économie des conventions, or French convention school, initially developed in the late 1980s by Luc Boltanski, François Eymard-Duvernay, Jean-Pierre Dupuy, Olivier Favereau, Robert Salais and Laurent Thevenot and now pursued by thousands of researchers around the world provides one such mirror.

\section{The EC on Justification: a primer}

Like Bhaskar, Boltanski and Thevenot (2006) start with the idea of judgment, though unlike Bhaskar their concern is not so much with the rational judgment of scientists, 
but more with the general conditions under which judgments made by social agents are or can be made legitimate. While the primary concern of Bhaskar and Lawson is with how knowledge can be justified and truth be (tentatively) established, Boltanski and Thevenot are principally interested in how social objects and configurations can be justified, and how legitimacy is established. They introduce their meta-theoretical framework with a lively example:

'Let us consider, for example, a dispute between two drivers after a collision. The furious indignation of the first can stem from a series of heterogeneous vexations he suffered the same day: his wife fell ill; his son had very bad grades at school; his boss humiliated him; he is anxious about a pain in his throat (maybe cancer) and, in addition to that, this stupid guy bumps into his new, beautiful car. That's too much! But the second driver can also have a series of personal reasons to complain against a nasty world: his mother just died the day before; his taxes have increased; his last book has been refused by the publisher and, moreover, there is this idiot, in the middle of the road. That's too much! If they want to escape violence they must be able to eliminate most of these motives of discontent as 'private' and to converge towards a common definition of the relevant objects in the situations - such as highway codes, states of tires, etc. But in order to converge in sorting out relevant and irrelevant items they must share a common capacity to see what fits the situation and under which relation. They need, hence, a common definition of the form of generality which allows to connect this situation with other ones identified as similar.' (Boltanski and Thevenot, 1999: 361).

There is certainly quite a bit to unpack in the above example and the last sentence, in particular, deserves additional explanation for readers unfamiliar with the économie des conventions. What do the authors mean by a 'form of generality'? And why does justification necessitate that 'the specific situation be connected with other ones identified as similar'?

Just as critical realism defends the principle that there are multiple ways of referring to a state of affairs (epistemological relativism), the économie des conventions supposes that there are multiple ways of describing and justifying a state of affairs. It does not follow that anything goes, but rather that, to be generalizable and understandable by other social agents, descriptions, justifications, valuations and critiques must follow a certain grammar. They must be expressed and assembled in certain ways that make them recognisable by other agents who are capable of using the same grammar. Some elements of this grammar are culturally and historically specific while others are universal across human societies (more on this below).

Whilst Boltanski and Thevenot do not use the idea of judgmental rationality explicitly, we believe it is nonetheless at the heart of their model of situated judgement. Indeed, they explicitly reject an irrationalist stance and argue instead that 'arguments have to be solid enough to be able to resist questions of an indeterminate number of new, not yet specified, partners' (Boltanski and Thevenot 2000: 214). Of central importance for our purposes, their framework provides a conceptual prism through which it is possible to compare and contrast CSO's judgemental rationality with the competing conception of judgment implicit in mainstream economic approaches. But let us illustrate the 
économie des conventions' basic features on the simpler example of the car accident mentioned above before mobilising it in the next section to compare the more complex and contested ideological configurations of CSO, mainstream economics theory and mainstream economics practice.

Boltanski and Thevenot analyse ideological configurations, aka polities or worlds of worth, by systematically studying how agents engage in justification and critique. To do so, they identify common higher principles through which agents extract themselves from their immediate situation and rise to a higher level of generality. For instance, while profitability constitutes the higher principle of the market world, it is second to efficiency in the world of production and to the collective will in the civic world. Thus, the same object, say a car accident will be valued according to its monetary cost in the market world (how much?), to the traffic inefficiencies generated in the industrial world (how many hours lost for how many drivers?) and to the respect of driving codes in the civic world (which rules have been broken by whom?)

Judgments of worth operate by bringing together persons and objects into homogeneous, recognisable, categories. This operation is designated by Boltanski and Thevenot as the qualification of persons and objects. Thus, whether a given object, say again a road accident, is qualified as a monetary loss or as a traffic perturbation or as an infringement to the law will determine in which world of worth its value will be justified. And conversely, justifying an accident's worth only in terms of its market value presupposes that we are dismissing other worlds of worth. Think, for example of a careless driver stopping after the collision and handing an envelope filled with bank notes while uttering: 'this should cover your costs, let's never talk about this again'.

To be legitimate, a polity must endow all participants with common humanity, that is, with equal capacity in principle to participate in social life by qualifying situations, issuing judgments of worth, issuing critiques and putting judgments to the test. With the exception of utopian homogeneous communities, the principle of common humanity coexists in tension with the fact that agents have differential access in practice to what they are all equally entitled to in principle. Thus, while every human being may in principle be able to determine who is at fault in a complex car accident (and thus act as a magistrate or judge), some individuals are deemed to be better qualified than others to exercise such judgments.

In a legitimate polity, the worth of a person or an object is regularly subjected to reappraisal through tests of worth. Thus a driver's worth will be confirmed or questioned depending on how she handles dangerous traffic situations unfolding while the tests of worth for a car will depend on the world of worth within which it is inscribed. A car's worth may be tested at the time of selling it (market world), when it is driven at speed on a rainy motorway (industrial world) or when it passes antipollution controls (civic world).

The coexistence of different polities encompassing different principles and tests of worth is naturally subject to conflict. Indeed, critique occupies a central place in Boltanski and Thevenot's model, and a substantial portion of their work retraces the various ways in which each polity can be mobilised to criticise a specific social configuration. Thus the driver responsible for the road accident can be criticised for having broken a rule (civic world), for having lost control of his/her car (industrial 
world) or for having generated a monetary loss (market world). But ideological configurations, as much as the social objects which are inscribed in them, can be the target of critique. As an illustration, critiques from the civic world can be mobilised towards the market world (deemed to be unfair because it privileges haves over have nots) and towards the industrial world (deemed to privilege performance at the expense of respect for due procedure).

The preceding summary of Boltanski and Thevenot's model provides us with the basic lens through which we may now examine the modes of justification employed by CSO in contradistinction with those employed by mainstream economics.

\section{Justification in CSO and Mainstream Economics: an EC perspective}

We now mobilise Boltanski and Thevenot's approach to make sense of the dialogue of the deaf between CSO and mainstream economics. One difficulty is that the practices and the theories of mainstream economists are frequently, and normally, out of touch (see Dequech 2017 for a recent discussion). Leamer (1978) famously argued that the practice and theory of mainstream economics are largely disconnected. As he put it:

'The opinion that econometric theory is largely irrelevant is held by an embarrassingly large share of the economics profession. ... We comfortably divide ourselves into a celibate priesthood of statistical theorists, on the one hand, and a legion of inveterate sinner-data analysts, on the other. ... I began thinking about these problems when I was a graduate student in economics at the University of Michigan, 1966-1970. At that time there was a very active group building an econometric model of the United States. As it happens, the econometric modelling was done in the basement of the building and the econometric theory courses were taught on the top floor (the third). I was perplexed by the fact that the same language was used in both places. Even more amazing was the transmogrification of particular individuals who wantonly sinned in the basement and metamorphosed into the highest of high priests as they ascended to the third floor.' (Leamer 1978: vi)

The near schizophrenic situation described by Leamer encourages us to distinguish, in our analysis, between the ideological configuration of mainstream economics theory and the ideological configuration of mainstream economics practice. A careful reader might also query on what basis can we assume an equivalence between 'econometrics', 'mainstream economics' and 'mainstream modelling'. This equivalence is justified in light of the arguments developed by Lawson (2006: 491-495), Cf. section 1 above.

The EC model outlined above (section 3) provides us with an analytical lens that allows us to observe CSO and mainstream economics theory and practice as ideological configurations. More specifically, the EC model invites us to systematically flesh out, compare and contrast otherwise taken for granted assumptions regarding each ideological formation's common higher principle; qualification of persons and objects; principles of common humanity and legitimate tests of worth.

\subsection{Common higher principles}


Researchers operating from within each of these ideological configurations must espouse a common higher principle in order to attain a level of generality that allows them to transcend purely subjective judgments. Differences in these principles are expressed explicitly in the case of CSO and mainstream economics. As we saw in the discussion of the CSO's contrastive method, the proximate objective of theorising is to explain the range of causal mechanisms underlying observable patterns in events. And this common higher principle is anchored in at least two further values: an epistemic commitment to truth and a normative commitment to emancipation, both inherited from critical realism. In contrast, since Friedman's (1953) intervention, the proximate objective of mainstream theorising has been predictive success. Again, this common higher principle masks a deeply held epistemic commitment to mathematical rigour, and a normative commitment to technocratic utility and policy relevance. However, mainstream economic practice has notably failed to produce accurate predictions of future states of affairs and even trend prediction seems to be beyond the grasp of most mainstream modellers. This has led mainstream economists to retreat to a different proximate goal in practice: disciplinary prestige. To produce 'good economics' has become a very complex and difficult task that is highly prized within the academy and (at least until recently) outside it. The underlying epistemic commitment to mathematical rigour remains, but it is underpinned by a different (in this case aesthetic) commitment to the elegance and simplicity of models rather than the production of accurate predictions.

\subsection{Qualification of persons and objects}

The process of 'qualification' is also radically different across polities. The CSO approach presupposes that social entities are concept-dependent and thus recognizes that social science (including economics) are characterized by 'an inescapable hermeneutic moment, one that (...) may be of greater consequences than any similar or comparable moment in natural science.' (Lawson 1997: 35). Participants' reasons should not only be interpreted, but their causes and effects should also be explained in terms of causal mechanisms discovered via the investigation of surprising contrasts. On the other hand, mainstream economics in theory focusses on the quantifiable data of observed reality, and, in practice, is heavily constrained by the technical toolkit that dominates the profession (though its content may change over time). And these differences have significant consequences for the ways in which judgments are put to test and justifications are produced. Whilst the contrastive method suggests that prediction will be difficult to attain outside controlled settings and focusses on the discovery of hitherto unidentified causal mechanisms, mainstream economists maintain that accurate predictions are possible and advocate rigorous econometric testing. Failure to predict economic events has led, however, to the development of other tests in practice. Rather than accurate forecasts, quality is established via a self-referential process involving the laborious scrutiny of models in the peer review process of leading journals. If publication in one of a very small number of such prestigious journals is secured, the value of the publication becomes a tradeable commodity that is not necessarily connected to the content of the article. In many cases such publications will secure career advancement for the author.

It is worth noting that CSO researchers are subject to similar social constraints as long as they attempt to maintain a position in an academic economics department. Anecdotal evidence indicates that CSO researchers who had obtained top marks in mathematical degrees from top universities had either to accept teaching-focused positions or had to 
pursue their careers in departments less obsessed with mainstream economics' modes of qualification. These survival routes include universities outside the English speaking world and business schools.

\subsection{Principles of common humanity}

The principles of common humanity that underpin each approach are also at odds. The CSO follows the social sciences in positing reflexive human subjects, partially constituted by the relations that they have with each other. Human reflexivity extends beyond lay people's ability to interpret social situations and also encompasses their ability to understand the conclusions of economists/social scientists and orient their activities accordingly. This 'double hermeneutic' (a term coined by Giddens 1984 but re-employed by Lawson 1997: 197; 2009: 279-80) establishes a symmetry, in terms of human dignity, between laymen and economists.

In contrast, mainstream economists focus on the economic agent as an isolated atom. Mainstream economic theorists arrived at a well-defined conception of the economic agent as a rational optimiser (whether individual or collective) which guarantees a common humanity of economic subjects across models but which falls short of maintaining a symmetry between the researcher and the researched. In practice this conception of rational atomistic agents has become increasingly flexible in order to accommodate new theoretical ideas emanating from within the discipline, but the reflexive and relational features of human subjects have continued to be ignored since they cannot be incorporated into the standard technical toolkit. While an impoverished yet common humanity of agents is still maintainable in the specific context of each model, the multiplication of models has generated a corresponding multiplication of conceptions of humanity. Moreover, the interpretation of mathematical rigour as modelling prowess has encouraged the introduction of unreal, and ultimately inhuman, characteristics beyond atomicity and rational optimization (for a defence of unrealistic assumptions, see Kanazawa 1998). These include, depending on models, infinitely lived individuals, agents capable of accessing and processing complete information, or endowed with perfect memories, and so on.

\subsection{Tests of worth}

Partly because of the above differences, CSO and mainstream economics rely on very different ways of testing the legitimacy of their own judgements. While CSO recognizes the fallibility and relativity of knowledge claims, it also defends a conception of judgmental rationality that posits that products of academic activity can and should be judged on the basis of their relative power to explaining surprising states of affairs. We have examined in section 2 (above) some of the internal limitations of tests of legitimacy based on CSO's ontological and epistemological premises as CSO determines some aspects of the dynamics of justification while leaving others open to discussion between participants.

Yet, the internal limitations of CSO's judgmental rationality and associated tests do not allow us, on their own, to understand the dialogue of the deaf with mainstream economics. This deafness can only be understood if we also appreciate how further apart mainstream economics' tests of legitimacy are from CSO's. Indeed, mainstream theorists evaluate the legitimacy of economic theories with regards to their predictive power. One consequence is that they have little patience for explanatory projects. The only version of explanation they are ready to accept as legitimate must conform to 
something like Hempel's deductive-nomological model. That is, a version of 'explanation' that corresponds to a specific case of past-oriented prediction (for a defence of this approach to explanation, see Hempel 1965).

Another, equally important consequence of valuing predictive power, is that tests of worth based on predictive success have failed repeatedly over the past 50 years or so. No sooner a prediction seems confirmed that new data disconfirms it (Lawson 1997, ch. 7). The response of mainstream modellers is, however, telling. Rather than discrediting their own ideological configuration, they seem to have protected it by having recourse to a less damning test consisting in showcasing mathematical prowess. Hence, Friedman's observation that 'economics has become increasingly an arcane branch of mathematics rather than dealing with real economic problems.' (Friedman, 1999: 137, cited in Lawson 2006: 490),

While mainstream economic theory views CSO explanations as partial and imperfect approximations of a properly scientific explanation (as past-oriented reversed prediction), the gap is even wider when we consider the tests of legitimacy employed by practitioners, rather than theorists, of mainstream economics. The slip from tests of worth based on prediction to tests of worth based on mathematical prowess are, of course, at the heart of the efforts, hopes and fears of practicing economists. But on these theoretical tests are intertwined with other, more institutional, tests employed when valuing the worth of an economist. The latter include securing promotion through publication in prestigious journals and by securing influence outside academia, for instance by obtaining roles in private or national banks, in political think tanks, and so on. And conversely, authors who have not succeeded through these rites of passage are considered either as failed economists or as researchers in a different field of the social sciences.

\section{Discussion: cracks in the mainstream citadel}

Through these contrasts we can see how CSO, mainstream theory and mainstream practice constitute quite different ideological configurations. The gulf between the mainstream and CSO is not merely explainable by reference to different languages and different theoretical assumptions about the nature of their objects of study. If that were the case, then some of these gaps might have been bridged during the last thirty years. Rather, the ongoing dialogue of the deaf is the by-product of the adoption of completely different normative frameworks of justification. And, since these frameworks anchor judgments within each polity, conflict between polities cannot be settled by using them. While our assessment of mathematical modelling's hegemony is largely congruent with Lawson (2006, 2012b), our EC analysis also highlights aspects which are arguably downplayed by Lawson and indicate potential weaknesses in the mainstream hegemony.

The first weakness is that the practices of mainstream economics are, from an EC perspective, open to contestation on the grounds of their violation of the principle of common humanity. Indeed, mainstream economists presuppose differences between scientists and laypersons that can be interpreted, from a perspective that values equal human dignity, as an arrogant stance held by 'experts' in the face of 'common people'. It is noteworthy that the discussions preceding the United Kingdom's recent referendum on exiting the European Union highlighted defiance of the British 
population at large towards 'experts' in general and towards economists in particular. Perhaps approaches influenced by CSO and based on observation, discussion with economic agents and on the formulation of fallible hypotheses - rather than on obscure and failing mathematical models - could win again the hearts of the general public including university students? (see Favereau 2015 for an insightful account of orthodox economists' arrogance towards heterodox colleagues).

The second weakness is that, while CSO's critique of mainstream economics has developed by examining the latter's ontological assumptions, another, perhaps more effective critique, might focus on the tests of legitimacy employed by mainstream economics. And critiques addressing the fact that theorists have failed to predict over sustained periods of time or that they have been more concerned with departmental politics than with the quest for truth are perhaps likely to gather more traction than critiques of questionable ontological presuppositions. Indeed, our succinct économie des conventions analysis invites us and our readers to contemplate future research on the organisation of tests of legitimacy within those organisations employing economists. Thus, rather than seeking a grand narrative in terms of the domination of mathematical modelling in Western Society, as Lawson does quite successfully, our paper invites researchers to retrace the various struggles through which mainstream economics' tests of legitimacy have grown in importance in universities and other academic institutions. Such studies could, at their most basic level, consist of a longitudinal comparison of exam scripts in reputable departments of economics. The apparition, and then dominance, of mathematical exercises could be valuably put in perspective by documentary analysis of minutes, memoirs of scholars and, perhaps, interviews of emeriti who lived long enough to still remember earlier practices. More complex studies might also establish links between the transformation of tests of worth with the spread of neo-liberal think tanks in the McCarthyite USA and anti-communist Britain (see the works of Djelic on the creation of Atlas, esp. Djelic 2014).

We believe that attending to these, sometimes downplayed or forgotten struggles, might shed light on now defunct but eventually or partly resurrectable, tests of legitimacy for the community of academics interested in the study of economic phenomena (see AlAmoudi and Latsis 2015 for a social theoretical account of institutional death and the significance of forgotten struggles).

\section{$\underline{\text { Conclusion }}$}

The EC framework allows us to go further than merely noting the absence of dialogue between CSO and mainstream economics. It offers us a prism through which CSO can be compared and contrasted with the theory and practice of mainstream economics. Our EC prism allows us to avoid ad hominem considerations and to identify fundamental differences impeding dialogue between the two approaches to the study of economic phenomena. We have illustrated how the two programmes differed in terms of their higher common principles, the way they qualify persons and objects, the demands they put on common humanity and the trials through which claims to validity are tested and judged.

By adopting an EC grid of analysis, we could provide a systematic examination of the basic disputes between CSO and the theory and practice of mainstream economics. Although we acknowledge our sympathy for the CSO programme, it is also our belief 
that the EC framework facilitated a comparison that is more impartial than if it had been formulated from within a single programme.

In this respect, the greatest advantage of the EC framework is that it has helped us to step back and delineate some of the limits of the judgmental rationality that is at the heart of the CSO approach. Indeed, CSO takes for granted higher common principles based on truth and human emancipation. By doing so, it fails to convince interlocutors who would regard truth and emancipation in high esteem but would nonetheless privilege further another (set of) values. While we have no doubt that mainstream economists hold some regard for truth and human emancipation, our analysis indicates that mainstream theorists hold predictive accuracy in even greater esteem while practitioners of economics seem particularly enthused by mathematical elegance and securing influence over decision -making. But these differences concern neither the nature of the world, nor the nature of knowledge, but rather the nature of the values at the heart of the economic sciences, and the structure of those tests through which academic worth is evaluated. Behind the grand narrative of the hegemony of science as mathematics (Lawson 2012b), our approach attracts attention to small scale struggles through which current tests of legitimacy came to be established. Our analysis also invites us to observe and imagine struggle tactics that may invalidate or replace them. And behind the ontological and epistemological dispute opposing CSO to mainstream economics, our study also indicates the existence of an equally important axiological dispute.

\section{References:}

Al-Amoudi, I. and Latsis, J. (2015). 'Death contested: morphonecrosis and conflicts of interpretation.' In: Archer, M. S. (ed.) Generative Mechanisms Transforming Late Modernity. Springer, pp. 231-248

Al-Amoudi, I., \& Willmott, H. (2011). Where Constructionism and Critical Realism Converge: Interrogating the Domain of Epistemological Relativism, 32(1), 27-46. Bhaskar, R. (1979/2014). The possibility of naturalism: A philosophical critique of the contemporary human sciences. Routledge.

Bhaskar, R. (1975/2008). A realist theory of science. Routledge.

Boltanski, L., \& Thévenot, L. (2000). The reality of moral expectations: a sociology of situated judgement. Philosophical explorations, 3(3), 208-231.

Boltanski, L., \& Thévenot, L. (2006). On justification: Economies of worth. Princeton University Press.

Brown, A. and Roberts J.M. (2014). 'An appraisal of the contribution of critical realism to qualitative and quantitative research methodology: is dialectics the way forward?'. In: Edwards, P.K. et al. (Eds). Studying Organizations Using Critical Realism. Oxford: Oxford University Press.

Colander, D., Holt, R.P.F \& Rosser, B. (2004) 'The Changing Face of Mainstream Economics', Review of Political Economy, 16:4, pp. 485-499.

Cottrell, A. (1998). Realism, regularities, and prediction. Review of Social Economy, 56(3), 347-355.

Davidsen, B. I. (2005). Critical realism in economics-A different view. Ontology and Economics: Tony Lawson and his critics.

Davis, J. (2006) 'The Turn in Economics: Neoclassical Dominance to Mainstream Pluralism?' Journal of Institutional Economics, 2:1, pp. 1-20. 
Davis, J. (2009) 'The nature of heterodox economics' in E. Fullbrook [ed.] Ontology and Economics, pp. 83-92.

Dequech, D. Some institutions (social norms and conventions) of contemporary mainstream economics, macroeconomics and financial economics. Cambridge Journal of Economics. Bex014. doi: 10.1093/cje/bex014.

Djelic, M.-L. (2014) 'Spreading Ideas to Change the World: Inventing and Institutionalizing the Neoliberal Think Tank' in C. Garsten and A. Sörbom (eds) Political Affair: Bridging Markets and Politics. Edward Elgar,

Dow, S. C. (1999). Post Keynesianism and critical realism: what is the connection?. Journal of Post Keynesian Economics, 22(1), 15-33.

Downward, P., \& Mearman, A. (2009). Reorienting economics through triangulation of methods. Ontology and economics: Tony Lawson and his critics, 130-41.

Fleetwood, S. (1999). Critical realism in economics: Development and debate (Vol. 12). Psychology Press.

Favereau, O. (2015) 'Arrogance de l'économie, économie de l'arrogance.' In:

Enriquez, E. (Ed.) L'arrogance: un modele de domination néo-libéral. Paris: In Press. Fleetwood, S. (2005). Ontology in Organization and Management Studies: A Critical Realist Perspective. Organization, 12(2), 197-222.

Fleetwood, S. (2006). Rethinking labour markets: A critical-realist-socioeconomic perspective. Capital \& Class, 30(2), 59-89.

Fourcade, M., Ollion, E., \& Algan, Y. (2015). The Superiority of Economists. The Journal of Economic Perspectives, 29(1), 89-113.

Friedman, M. (1953/1994). The methodology of positive economics. The philosophy of economics: An anthology, 2, 180-213.

Fullbrook, E. (Ed.). (2009). Ontology and Economics: Tony Lawson and his critics. Routledge.

Giddens, A (1984) The Constitution of Society. Oxford: Polity.

Gingras, Y. (2001) What did mathematics do to physics. History of Science, xxxix, 383-416.

Guerrien, B. (2009). 'Irrelevance and ideology'. Ontology and Economics: Tony

Lawson and His Critics, 158.

Granger, C. (2004) 'Critical Realism and Econometrics: and Econometrician's Viewpoint'. In P. Lewis [ed.] Transforming Economics, pp 96-106.

Groff, R. (2000). The Truth of the Matter Roy Bhaskar's Critical Realism and the Concept of Alethic Truth. Philosophy of the Social Sciences, 30(3), 407-435.

Hausman, D. M. (1998). Problems with realism in economics. Economics and Philosophy, 14(02), 185-213.

Hausman, D. M. (1999). Ontology and methodology in economics. Economics and Philosoph y, 15(02), 283-288.

Hempel, C. (1965) 'The function of general laws in History', in Aspects of Scientific Explanation, New York: Free Press.

Henry, J. (1997) The Scientific Revolution and the Origins of Modern Science, New York: Palgrave MacMillan.

Hodgson, G. M. (1999). Evolution and institutions. Edward Elgar.

Hodgson, G. M. (2009). On the Problem of Formalism in Economics. Ontology and Economics: Tony Lawson and His Critics.

Kanazawa, S (1998). In defense of unrealistic assumptions. Sociological Theory, 16(2), 193-204.

Kline, M. (1964) Mathematics in Western Culture, Oxford: Oxford University Press. 
Latsis, J.S. \& Repapis, C. (2014). 'A model intervenes: the many faces of moral hazard'. Cambridge Journal of Economics, 38:4, pp. 743-760.

Lawson, J. (2007). 17 Economics and autism: why the drive towards closure? Contributions to Social Ontology, 15, 293.

Lawson, T. (1989). Realism and instrumentalism in the development of econometrics. Oxford Economic Papers, 41(1), 236-258.

Lawson T (1997) Economics and reality. Routledge.

Lawson, T. (2003). Reorienting economics (Vol. 20). Routledge.

Lawson, T. (2006). The nature of Heterodox Economics. Cambridge Journal of Economics, 30, 485-505.

Lawson, T. (2009). 'The mainstream orientation and ideology: a reply to Guerrien.' In: Fullbrook (Ed.) Ontology and Economics: Tony Lawson and his Critics. London: Routledge.

Lawson, T. (2012a). Ontology and the study of social reality: emergence, organisation, community, power, social relations, corporations, artefacts and money. Cambridge Journal of Economics, 36(2), 345-385.

Lawson, T. (2012b). Mathematical Modelling and Ideology in the Economics Academy: competing explanations of the failings of the modern discipline?.

Economic Thought, 1(1), 3-22.

Lawson, T. (2015). The nature of the firm and peculiarities of the corporation. Cambridge Journal of Economics, 39(1), 1-32.

Lawson, T. (2015). The Modern Corporation: the Site of a Mechanism (of Global Social Change) that is Out-Of-Control? In: M.S. Archer (Ed.). Generative Mechanisms Transforming the Social Order (pp. 205-230). Springer International Publishing.

Lawson, T. (2016). Social positioning and the nature of money. Cambridge Journal of Economics, 40(4), 961-996.

Leamer, EE (1978) Specification Searches: ad hoc inferences with non-experimental data. New York: John Wiley and Sons.

Lewis, P. [ed.] (2004) Transforming economics: perspectives on the critical realist project. Abingdon: Routledge.

Morgan, J. (2009). Private equity finance: rise and repercussions. Basingstoke:

Palgrave Macmillan.

Moureau, N. and Sagot-Duvauroux, D. (2008) La construction du marché des tirages photographiques. Etudes Photographiques, 22. URL :

http://etudesphotographiques.revues.org/1005. Last accessed on 30 June 2016.

Parsons, S. D. (1999). Economics and reality: a philosophical critique of transcendental realism. Review of Political Economy, 11(4), 455-466.

Pratten, S. (2005). Economics as progress: the LSE approach to econometric modelling and critical realism as programmes for research. Cambridge Journal of Economics, 29(2), 179-205.

Reed, M. I. (1997). In Praise of Duality and Dualism: Rethinking Agency and Structure in Organizational Analysis. Organization Studies, 18(1), 21. 